\title{
AMBIENTE, CONFLITOS E POVOS INDÍGENAS: PERSPECTIVAS CONTEMPORÂNEAS NA AMÉRICA LATINA
}

\author{
Thaís Janaina Wenczenovicz ${ }^{1}$ \\ Marlei Angela Ribeiro dos Santos ${ }^{2}$
}

\section{Resumo:}

A reflexão visa analisar a relação estabelecida pelos povos indígenas em face aos conflitos ambientais e a legislação nacional. Insta assinalar que os processos de violências físicas e estruturais empreendidas contra os povos indígenas assentam-se no ideário do colonialismo e da colonialidade do poder. Esses movimentos consolidaram com os processos de epistemicídios, etnocídios, genocídios e memoricídios nas mais diversas regiões da América Latina e do Brasil por extensão. O procedimento metodológico é o bibliográfico-investigativo, com reflexões a partir de aportes teóricos de pensadores do Grupo Modernidade/Colonialidade (GM/C) e afins.

Palavras-chave: América Latina; Ambiente; Brasil; Conflitos; Povos Indígenas

\section{ENVIRONMENT, CONFLICTS AND INDIGENOUS PEOPLES: CONTEMPORARY PERSPECTIVES IN LATIN AMERICA}

\begin{abstract}
:
The reflection aims to analyze the relationship established by indigenous peoples in the face of environmental conflicts and national legislation. It urges to point out that the processes of physical and structural violence carried out against indigenous peoples are based on the ideals of colonialism and the coloniality of power. These movements consolidated with the processes of epistemicides, ethnocides, genocides and memoricides in the most diverse regions of Latin America and Brazil by extension. The methodological procedure used is the bibliographic-investigative, with reflections from theoretical contributions of thinkers from the Modernity / Coloniality Group (GM / C) and others.
\end{abstract}

Keywords: Latin America; Environment; Brazil; Conflicts; Indian people

\section{INTRODUÇÃO}

Pensar as coletividades com base na sua constituição sócio-histórica-cultural tem sido um movimento realizado por diversos pesquisadores em múltiplas áreas do conhecimento. Em se tratando de América Latina há quase meio século, cientistas vem

\footnotetext{
${ }^{1}$ Docente Adjunta e Pesquisador Sênior na Universidade Estadual do Rio Grande do Sul/UERGS. Professor colaborador do Programa de Pós-Graduação em Educação na Universidade do Oeste do Paraná/UNIOESTE. Professora Titular no Programa de Pós-Graduação em Direito/UNOESC.

${ }^{2}$ Discente Programa de Pós-Graduação em Direito/UNOESC.
} 
alertando sobre os perigos da continuidade do modelo de dominação existente dos seres humanos sobre a natureza. É com base neste cenário que o Novo Constitucionalismo desponta com iniciativas e proposições para implantação de uma mudança paradigmática, ou seja, positivação dos direitos a natureza (ecocentrismo).

As implementações de ordem normativa constitucional do ordenamento de alguns países da América Latina foram consideradas uma inovação evolutiva para a concepção do ambiente como um todo, inclusive primando pela manutenção de culturas e povos indígenas, fato que demonstra claramente que a convivência e responsabilidade social comportam uma responsabilidade social ética, da mesma forma as legislações permeadas pelos ramos do direito consideram relevante o patrimônio cultural, histórico, étnico, humano, elementos inerentes à importância da sustentabilidade.

A construção de epistemologias novas e a educação ambiental devem estar fundamentadas na ética da conduta humana em relação ao ambiente, fazendo emergir uma compreensão de que o homem tem a necessidade e o dever de preservar os recursos naturais essenciais à perpetuação de todas as espécies de vidas existentes no planeta, para além dos mecanismos legais, se faz necessária a adoção de novos paradigmas ambientais, sociais e humanos, mantendo a higidez da possibilidade de renovação intergeracional.

O estudo divide-se em duas partes. A primeira aborda algumas questões relacionadas à formação sócio-histórica das Comunidades Indígenas na América Latina. A segunda parte discorre sobre o Ambiente Sujeito de Direito: Sustentabilidade, Uma Escolha Ética. Utiliza-se do procedimento metodológico bibliográfico-investigativo.

\section{COMUNIDADES INDÍGENAS NA AMÉRICA LATINA}

Por muito tempo as comunidades indígenas na América Latina foram vistas como um entrave ao desenvolvimento. Assolados por doenças, perda de seus territórios e violências estruturais e simbólicas (processos de aculturação e assimilação), vivem séculos sob a égide da sobrevivência.

Nesse contexto, cumpre-se indicar que há um componente comum: a quase extinção do povo indígena latino-americano, seja ela física ou etnocultural. No primeiro caso, a população indígena, predominante na região nos tempos da colonização, hoje representa cerca de $10 \%$ da população latino-americana. Encontra-se concentrada principalmente em cinco 
países: Bolívia, Equador, Guatemala, México e Peru. No segundo caso, os índios latinoamericanos passaram por um processo de aculturação tão significativo que dificilmente podese falar hoje de etnias e culturas indígenas autênticas. Muito se perdeu de sua identidade com a eliminação de tribos inteiras e com a assimilação da cultura do colonizador.

Em virtude da exploração colonial e do colonialismo, as comunidades indígenas perderam suas terras, seus costumes próprios, suas tradições milenares - fonte de sua sobrevivência. Isso acarretou uma piora sensível da sua condição de vida, colocando-os em uma severa condição de pobreza. Em alguns países, como no Brasil, o Estado demarcou reservas indígenas em todo o território nacional, na tentativa de lhes garantir a subsistência.

Segundo o Relatório da Comissão Econômica para a América Latina e Caribe, um dos maiores desafios que a região enfrenta em sua busca pela igualdade é a inclusão dos direitos dos povos indígenas entre as prioridades das políticas públicas. Os desafios são enormes se considerarmos que na América Latina, como se examina neste estudo, existem mais de 800 povos indígenas, com uma população próxima de 45 milhões, que se caracterizam por sua ampla diversidade demográfica, social, territorial e política, desde povos em isolamento voluntário até sua presença em grandes assentamentos urbanos. A isto se acrescenta que o crescimento econômico registrado na região é altamente dependente dos recursos naturais e de seus preços internacionais, enquanto se observa uma governança deficiente destes recursos. A reprimarização da economia provocou fortes pressões sobre os territórios dos povos indígenas e desencadeou numerosos conflitos socioambientais ainda não resolvidos (CEPAL, 2015).

Diversos estudos apontam que após o ano de 2000, os povos indígenas em diversos espaços da América Latina ressurgiram enquanto voz partícipe dos processos sociais assentados em um novo modelo de constitucionalismo. De acordo com Borges e Carvalho:

\footnotetext{
É nas terras ameríndias, no século XXI, que nasce o Novo Constitucionalismo latino-americano. Os principais Textos Políticos em que se manifestam são as Constituições do Equador (2008), e da Bolívia (2009). Seus traços dominantes podem ser expostos na interculturalidade, na plurinacionalidade e no pluralismo jurídico (BORGES \& CARVALHO, 2019, p. 03).
}

O Novo Constitucionalismo latino-americano para Rubén Martínez Dalmau teve a pretensão de reformulação do Estado com vista ao reconhecimento da diversidade cultural de seus povos, rompendo em definitivo com o colonialismo eurocêntrico. A Constituição Colombiana é um divisor de águas, representando dois momentos distintos: um antes e um 
depois do constitucionalismo latino-americano. Outras Constituições também foram promulgadas seguindo essa linha, tais como: Equador (1998), Venezuela (1999), e Bolívia (2006-2007/2009). Porém, para os autores, o exemplo da Venezuela é o mais próximo do que viria a ser então denominado de Novo Constitucionalismo na América Latina (MARTÍNEZ DALMAU; VICIANO PASTOR, 2013).

Wolkmer colabora assentado nas diferenças e no diálogo entre as culturas:

[...] Pode-se caracterizar que este novo constitucionalismo de tipo plural e intercultural traduz um movimento popular de exigibilidade de uma nova "mirada política", com mudanças institucionais profundas, um constitucionalismo que vem das bases e é por esta influenciado, um "constitucionalismo desde abajo"; no qual o poder constituinte popular se sobrepõe ao poder constituído (...). Compõem-se numa manifestação política popular, participativa e atuante de diversos setores, alguns historicamente marginalizados e isolados por um pensamento e prática políticojurídica eurocêntrica (WOLKMER; FAGUNDES, 2013, p. 339)

O movimento emergiu da necessidade histórica de se garantir, através da positivação constitucional, alguns instrumentos de lutas e reivindicações de movimentos sociais de diversos segmentos sociais da América Latina, visando, assim, a participação popular sobre as políticas públicas, assentadas na interculturalidade, na plurinacionalidade ${ }^{3}$ e no pluralismo jurídico.

Para Agustín Grijalva (2010), a variedade de culturas estará presente quando diversos grupos humanos aglomerarem-se em um mesmo território (pertencente a um único Estado), cada um deles com seus próprios costumes, língua, origens, etc. Quando o Estado reconhece a existência desta diversidade cultural em seu país, através de sua Constituição, é sinal de que aprendeu a conviver com esta diversidade, e que busca o intercâmbio e o diálogo entre as culturas, e não a dominação de uma delas sobre as demais.

Esse cenário resultou na promulgação de diversas constituições, entre elas a Constituição da Bolívia, Equador em 2008 e Venezuela. A título de exemplo, é possível indicar entre outros aspectos dos povos indígenas latino-americanos após esse processo de ressignificação no processo cidadão e participativo, índices de melhoria na educação e na saúde. Em relação à educação, houve aumento nas taxas de frequência escolar, com porcentagens de comparecimento entre $82 \%$ e $99 \%$ para crianças de 6 a 11 anos. Quanto à

\footnotetext{
${ }^{3} \mathrm{O}$ Estado plurinacional é aquele em que as pessoas que nele residem são consideradas nacionais pela identificação pessoal que possuem com este Estado e pelo simples fato de ali estarem (ÁVILA SANTAMARÍA, 2008, p. 195-197).
} 
saúde, houve diminuição das taxas de mortalidade infantil - as mortes de crianças menores de cinco anos reduziram-se entre 2000 e 2010, nos nove países com dados disponíveis (Costa Rica, México, Brasil, Venezuela, Equador, Panamá, Guatemala, Peru e Bolívia) (ONU, 2014).

Consoante a essa realidade, os conhecimentos ancestrais, as inovações e as práticas tradicionais dos povos indígenas para a conservação e a utilização sustentável da diversidade biológica, assim como o desenvolvimento das diferentes modalidades coletivas das economias indígenas, oferecem uma oportunidade valiosa para a construção de um novo paradigma do desenvolvimento, baseado em uma mudança estrutural rumo à igualdade e sustentabilidade. É fundamental o reconhecimento da contribuição dos povos indígenas nos desafios que traz consigo o porvir de uma América Latina soberana (CEPAL, SÍNTESE, 2015).

A trajetória de luta dos povos indígenas pela defesa e reconhecimento de seus direitos foi contínua e persistente na construção da história dos países latino-americanos. Este legado de reivindicação e reconhecimento ganhou espaço em um quadro de direitos que se fundamentam em dois grandes marcos: o Convênio sobre Povos Indígenas e Tribais de 1989 $\left(\mathrm{N}^{\circ} .169\right)$ da OIT, que reconhece pela primeira vez seus direitos coletivos, e a Declaração das Nações Unidas sobre os Direitos dos Povos Indígenas (2007), que propõe o direito desses povos à livre determinação. Por sua vez, o padrão mínimo de direitos dos povos indígenas, obrigatório para os Estados, articula-se em cinco dimensões: o direito a não discriminação; o direito ao desenvolvimento e bem-estar social; o direito à integridade cultural; o direito à propriedade, uso, controle e acesso às terras, territórios e recursos naturais; e o direito à participação política.

Em âmbito internacional, existem dois mecanismos diretos de proteção dos Direitos Humanos, incluindo os direitos dos povos indígenas: o sistema das Nações Unidas e o Sistema Interamericano de Direitos Humanos da Organização dos Estados Americanos (OEA). Neste último, as sentenças da Corte Interamericana de Direitos Humanos, que tem caráter vinculante para os Estados, foram relevantes no novo ordenamento jurídico internacional no tocante aos direitos dos povos indígenas. No caso das Nações Unidas, os órgãos e mecanismos de proteção adquirem uma indiscutível relevância política para o reconhecimento e aplicação dos direitos dos povos indígenas.

Nesse contexto, S. James Anaya colabora dizendo que:

El sistema internacional contemporáneo reconoce abiertamente ahora que es un imperativo de derechos humanos el dar respuesta a las demandas de los pueblos 
indígenas. [...]. Sea como sea, lo cierto es que puede hablarse ahora de un régimen de derechos indígenas dentro del derecho internacional de los derechos humanos; un régimen todavia em desarrollo y que, en certa medida, beneficia a los pueblos indígenas (ANAYA, 2004, p. 30).

De uma forma objetiva, existem no sistema universal de proteção dos direitos humanos das Nações Unidas: a) mecanismos baseados na Carta das Nações Unidas, como o Conselho de Direitos Humanos, os procedimentos especiais, o exame periódico universal e órgãos assessores (como o Mecanismo de Peritos sobre os Direitos dos Povos Indígenas); b) mecanismos baseados na aplicação dos principais tratados vinculantes do direito internacional sobre os direitos humanos por parte dos países que os ratificaram. Geralmente os mecanismos que também são denominados 'comitês', há presença de especialistas. No aspecto acessibilidade, há diversas possibilidades para apresentar registros ao Conselho de Direitos Humanos, aos comitês e aos procedimentos especiais, garantindo assim o acesso ao sistema em casos de demandas emergenciais e urgentes.

Inúmeros são os exemplos de países na América Latina que desenvolveram ações e políticas públicas de valorização às comunidades nativas em justificativas que nas áreas por eles habitadas consta-se o papel protetor exercido pelos povos indígenas, até então, é pouco conhecido e reconhecido. A título de exemplo, pode-se citar as ações desenvolvidas pelo México nos últimos 5 anos. Embora os povos indígenas representem apenas $5 \%$ da população mundial, as regiões que habitam contém cerca de $80 \%$ da biodiversidade e possuem vários recursos naturais. Entretanto, sabe-se que tanto a propriedade como o 'controle' dos territórios nativos seguem mal definidos, em amplas áreas como na Ásia, África e América Latina. ${ }^{4}$

Relatórios elaborados através da Comissão Interamericana de Direitos Humanos (CIDH), e o Escritório Regional para América do Sul do Alto Comissariado das Nações Unidas para os Direitos Humanos (ACNUDH), indicam que as terras indígenas possuem um impacto de preservação maior que em terras de não-indígenas, especialmente no que tange a conservação da vegetação nativa. Importante destacar, que a vegetação nativa é importante para a regulação do clima e da vazão dos rios, a provisão de água e energia, o controle de pragas e polinização em diversos cultivos, propiciando inclusive condições para o aumento da produtividade agrícola.

\footnotetext{
${ }^{4} \mathrm{O}$ Acordo de Paris marcou o reconhecimento dos direitos das comunidades nativas e seu papel na proteção do clima e na luta contra a mudança global. No entanto, protestos e conflitos violentos em várias partes do Brasil demonstram que os direitos indígenas à terra permanecem sendo fonte de um conflito constantemente.
} 


\title{
2. AMBIENTE SUJEITO DE DIREITO: SUSTENTABILIDADE UMA ESCOLHA ÉTICA
}

A tutela do ambiente no direito brasileiro carrega a ideia que a espécie humana é o centro da tutela ambiental, ou seja, o direcionamento do bem jurídico protegido não é basicamente o complexo natural e sim um elemento que compõem este.

\begin{abstract}
Assim é que a adoção do marco jurídico-constitucional socioambiental resulta de um projeto político de consolidação dos direitos humanos sob o enfoque do desenvolvimento sustentável. A própria ideia de sustentabilidade, com a tutela integrada do ambiente e dos direitos individuais e sociais, embora extremamente importante, resulta na promoção de uma existência humana digna, relegando o meio ambiente como mero meio para tanto e, não, como um fim em si mesmo, ou seja, a natureza e seus componentes bióticos são classificados dogmaticamente como instrumentos de promoção da qualidade de vida do ser humano, com valoração moral meramente reflexa ou indireta. De acordo com esse entendimento prevalente, o âmbito de proteção do direito à vida, assim como o próprio conceito de mínimo existencial material, diante do quadro de risco ambiental, projeta sua eficácia em direção ao homem e somente a ele (SAMPAIO, 2015, p. 10).
\end{abstract}

Na mesma lógica, são utilizados princípios basilares para otimização e aplicação da lei no caso concreto, tais princípios são normas impositivas consoantes ao constitucionalismo jurídico que visam assegurar o bem tutelado, assim alguns princípios são considerados essenciais na esfera ambiental como por exemplo: da prevenção, da precaução, do poluidorpagador, desenvolvimento sustentável, elucidam que o ambiente deve ser manejado e cuidado de forma à evitar, precaver, restaurar, minimizar e à se restaurar.

O Direito Ambiental tem a tarefa de estabelecer normas que identifiquem como verificar as necessidades de uso dos recursos ambientais. Não basta a vontade de usar esses bens ou a possibilidade tecnológica de explorá-los. É preciso estabelecer a razoabilidade dessa utilização devendo-se, quanto a utilização não seja razoável ou necessária, negar o uso, mesmo que os bens não sejam atualmente escassos (MACHADO, 2009, p. 62).

O arcabouço de legislação ambiental brasileira é vasto, em nível federal, estadual, municipal e inclusive internacional que declaram e resguardam o ambiente ao exemplo da Convenção da ONU sobre as Mudanças Climáticas: COP $25^{5}$. Ademais, a existência das leis,

\footnotetext{
${ }^{5}$ A $25^{\text {a }}$ Conferência da ONU sobre o Clima - COP25 (sediada em Madri após a desistência do Chile devido à instabilidade social no país), é a atual Conferência das Partes da Convenção-Quadro das Nações Unidas sobre
} 
sabe-se que a educação e a gestão ambiental tem papel fundamental na elaboração de um sistema eficaz de sustentabilidade ambiental, pela conscientização e conhecimento dos indivíduos no desenvolvimento, social, urbano, educacional, político, econômico, envolvendo um aspecto moral e ético e uma sociedade envolvida na responsabilidade ambiental.

O que se quer dizer, todavia, é que não se deve aguardar que os cidadãos sejam educados para que então sejam instalados a participar. $\mathrm{E}$ isto porque, de fato, a própria participação já se apresenta como meio de se educar a população acerca dos assuntos ambientais fazendo com que cresça a conscientização e se lute em sua defesa. Sendo assim, entendemos que a educação ambiental não é apenas o exercício da cidadania ambiental, mas também é fim desta (ARTINGAS, 2004, p. 113).

Sirvinskas (2009) escreve que a educação ambiental deve estar fundamentada na ética ambiental. Entende-se por ética ambiental o estudo dos juízos de valor e da conduta humana em relação ao ambiente. Em outras palavras, a compreensão que o homem tem a necessidade de preservar ou conservar os recursos naturais essenciais à perpetuação de todas as espécies de vida existentes no planeta Terra. Essa compreensão está relacionada com a modificação das condições físicas químicas e biológicas do meio ambiente, ocasionada pela intervenção de atividades comunitárias e industriais, que pode colocar em risco todas as formas de vida do planeta. O risco da extinção de todas as formas de vida deve ser uma preocupação da ética ambiental.

O preceito constitucional exige que o Poder Público crie mecanismos eficientes para realização de uma gestão ecológica planejada das espécies. Assim promover o manejo ecológico das espécies é realizar uma gestão ecologicamente planejada das espécies da fauna e da flora ameaçadas de extinção, transferindo-as de um local para o outro com a intenção, de evitar a extinção em um determinado ecossistema (SIRVINSKAS, 2009, p. 78).

O entendimento ocidental sobre direito do ambiente é antropocêntrico, justificando o viés de que o homem é o centro de tudo e sua vontade é primordial independentemente de ser uma opção pela sustentabilidade ou não. Necessário é o entendimento de que os recursos naturais são considerados primordiais para a economia mundial, desenvolvimento econômico e de satisfação humana, ficando em segundo plano o elemento essencial da manutenção da subsistência natural e todas as espécies.

Mudança do Clima (UNFCCC, na sigla em inglês) encarregada de garantir que a Convenção e o Acordo de Paris de 2015 que a fortalece estejam sendo implementados (ONU, 2019). 
A conduta do homem em relação aos bens disponibilizados em potência na natureza, desde os tempos mais antigos até hoje sempre foi imediatista, irracional, sem respeitar aos princípios da prevenção e precaução, tão necessários para evitar que o ar puro que respiramos para beber não apenas esteja puída nos rios, mas sequer exista disponível nas prateleiras dos supermercados. Não há dúvidas de que, se continuarmos tentando essa postura irracional, de inversão de valores em relação aos bens de consumo, especialmente não dando a devida importância aos bens disponíveis na natureza, um dia não apenas vamos respirar ar poluído como já vem ocorrendo em várias cidades do planeta, mas vamos morrer asfixiados, e só vai sobreviver quem tiver dinheiro para comprar, nos supermercados, mascarás com tubos de oxigênio para respirar (RECH, 2009, p. 31-32).

Fatores relevantes que impuseram uma adoção de postura pedagógica e pluralista do Estado Constitucional do Equador sobre o conceito, direito e proteção do ambiente, culturas e povos, a exemplo da Constituição daquele país em 2008, que visa romper os domínios eurocêntricos e hegemônicos do sistema capitalista, salvaguardando o ambiente como o direito a um Buen Vivir, integrando o contexto natural e humano em sua plenitude.

Dentro do movimento constitucionalista sul-americano, particularmente na Constituição do Equador de 2008, um novo paradigma emergiu no cenário das discussões do direito ambiental, sobretudo porque foram reconhecidos os direitos da natureza, bem como o direito a um buen vivir, tendo como pano de fundo a cosmovisão dos povos indígenas andinos que exaltam a convivência harmônica entre homem e o meio ambiente natural (MALISKA, 2017, p. 149).

De outro tanto, no Brasil a personalidade jurídica se torna imprescindível para postular ou ter um direito resguardado diante de um pleito judicial, verdadeiramente a Constituição Federal de 1988, é clara em seu artigo duzentos e vinte e cinco declarando sistematicamente à espécie humana o direito do ambiente ecologicamente equilibrado, assegurando centralmente o direito na personalidade humana como titular de direitos e obrigações, deixando em segundo plano o ambiente. Seguindo deste entendimento para documento constitucional os artigos 170 e 231 da Constituição Brasileira de 1988, resguardam o ambiente como sendo um objetivo de ordem econômica e social brasileira:

Art. 170. A ordem econômica, fundada na valorização do trabalho humano e na livre iniciativa, tem por fim assegurar a todos existência digna, conforme os ditames da justiça social, observados os seguintes princípios: VI - defesa do meio ambiente. Art. 231. São reconhecidos aos índios sua organização social, costumes, línguas, crenças e tradições, e os direitos originários sobre as terras que tradicionalmente ocupam, competindo à União demarcá-las, proteger e fazer respeitar todos os seus bens (BRASIL, 1988). 
Consubstanciando o ordenamento jurídico, compreende-se que os direitos relacionados ao ambiente comportam a transindividualidade, em outras palavras, se refere à coletividade de indivíduos sem referência única e sim a totalidade, direitos difusos, coletivos e sociais, por fim visando o Estado democrático de direito.

O ordenamento jurídico brasileiro reconhece, então, a existência dos interesses transindividuais, para a sociedade contemporânea, é grande em virtude de quão complexa esta se torna a cada dia. Para se ter uma visão mais nítida de tal tipo de direito, faz-se necessária uma busca sobre o significado e o surgimento dos interesses transindividuais (BRASIL et al. 2009, p. 88).

Neste sentido, pode-se considerar que os direitos transindividuais se referem aos direitos coletivos e, principalmente, ao fundamento dos direitos humanos, contudo, entende-se que a humanidade está relacionada para o além do indivíduo que vive em centros urbanos ou propriedades rurais. Nesse contexto, refere-se também as comunidades indígenas e as mais variadas culturas existentes que tem uma íntima ligação de existência com o ambiente em si, assim a consciência e valorização étnica depende da segurança jurídica.

\begin{abstract}
A tutela é $m$ instituto jurídico que existe para assegurar direitos e não para obscurecê-los, subtraí-los ou negá-los. Ela na compreensão pura do instituto, não é uma condenação ou punição do tutelado, mas, ao contrário, protege-o contra os que pretendem turbar seus direitos (do tutelado). Da tutela só podem beneficiar-se aqueles que dela necessitam. E os não tutelados, ou seja, aqueles que podem exercer seus direitos em toda sua plenitude, do aspecto legal, também não são desprotegidos, na sociedade (SILVA 1985, p. 52).
\end{abstract}

Apesar do esforço legislativo de conferir as identidades indígenas os direitos inerentes a sua formação cultural, étnica e de propriedade originária, tais povos sofrem historicamente com os processos de aculturação e banimento de seu habitat natural. Segundo IBGE - Instituto Brasileiro de Geografia e Estatística (2010), no Censo 2010, o IBGE aprimorou a investigação sobre a população indígena no país, investigando o pertencimento étnico e introduzindo critérios de identificação internacionalmente reconhecidos, como a língua falada no domicílio e a localização geográfica. Foram coletadas informações tanto da população residente nas terras indígenas (fossem indígenas declarados ou não), quanto indígenas declarados fora delas. Ao todo, foram registrados 896,9 mil indígenas, 36,2\% em área urbana e 63,8\% na área rural. O total inclui os 817,9 mil indígenas declarados no quesito cor ou raça do Censo 2010 (e que servem de base de comparações com os Censos de 1991 e 
2000), e também as 78,9 mil pessoas que residiam em terras indígenas e se declararam de outra cor ou raça (principalmente pardos, 67,5\%), mas se consideravam "indígenas" de acordo com aspectos como tradições, costumes, cultura e antepassados.

\footnotetext{
Observe-se, contudo, que todo o esforço histórico de garantir aos índios os seus direitos sobre a terra que tradicionalmente ocupam jamais foi capaz de lhes garantir um domínio pleno sobre essas terras, ou seja, nunca lhes foi reconhecida a propriedade, mas tão só uma posse intransmissível e com uma série de limitações de uso (FRANÇOSI, 2015, p. 49).
}

Partindo desta análise, o direito ao ambiente é compreendido como um valor ético por intermédio de mecanismos normativos que pretendem ampliar a capacidade de tutela legal em relação ao exercício de direitos. Contudo, a proteção legislativa existente, mas ainda não alcança a eficácia de proteção integral do ambiente e a dignidade humana no sentido literal, inclusive em se tratando das comunidades indígenas.

\footnotetext{
O surgimento das questões ambientais no mundo do Direito é um fato extremamente importante e que tem gerado as mais relevantes consequências na vida prática das pessoas e empresas. É indiscutível que as justas necessidades da proteção do meio ambiente precisam se compatibilizar com os princípios constitucionais que regem a ordem jurídica democrática, muito embora nem sempre do conjunto de normas e princípios constitucionais que regem a ordem jurídica democrática, muito embora nem sempre isso ocorra (ANTUNES, 2012, p. 38).
}

Assim, compreendemos que existe uma necessidade além dos mecanismos legais, se faz necessário à adoção de novos paradigmas ambientais, sociais e humanos, visando atender a proposta expressa em documentos internacionais e constitucionais de forma a alcançar o desenvolvimento sustentável dos ecossistemas e dos espaços democrático de dimensão e proteção ao ambiente natural, cultural, étnico, social, sobre tudo intergeracional.

\section{CONCLUSÃO}

O contexto da trajetória histórica de um novo modelo de constitucionalismo, com enfoque especial ao fenômeno ocorrido na América Latina culminou com a reformulação do Estado, priorizando a diversidade cultural de seus povos, rompendo em definitivo com o 
colonialismo eurocêntrico, além de impulsionar significativas mudanças de caráter democrático nas Cartas Constitucionais, já que incorporou a cosmovisão indígena no texto constitucional equatoriano, trazendo consigo o reconhecimento de dois inovadores princípios: o Buen Vivir e a natureza enquanto sujeito de direito, e institucionalizou o modelo ecocêntrico, em oposição ao antropocêntrico, atribuindo direitos e personalidade jurídica a "Pachamama" (direitos da natureza).

A adoção do princípio do "bem viver" é a atribuição de diretos à natureza (Pachamama), ou seja, todos os seres vivos, atuam como partes integrantes da natureza, seriam titulares de direitos. A partir da década de 1980, grande parte dos países da América Latina promoveram a implementação democrática pelo novo constitucionalismo visando à proteção do ambiente, culturas e povos indígenas. Do mesmo modo, várias legislações foram implementadas ao longo do tempo buscando assegurar uma justiça ambiental e uma qualidade de vida condizente com a dignidade humana, e responsabilidade social e de uso comum do povo.

O ambiente comporta uma bagagem de trajetória histórica dos seres vivos, dos ecossistemas, culturas e saberes milenares dos povos indígenas, que são de responsabilidade comum que exige força global para assegurar a sustentabilidade. Modelos internacionais como o do Equador no estilo do Buen Vivir, somados aos esforços de tratados, convenções que resguardam mecanismos de ética ambiental devem ser aplicadas visando a manutenção de todas as espécies. Da mesma forma, os direitos transindividuais se referem aos direitos coletivos e principalmente ao fundamento dos direitos humanos incluindo as comunidades indígenas pela sustentabilidade intergeracional e a adoção de novos paradigmas que reconheçam o ambiente como primordial, os saberes milenares dos povos como instrumento de sustentabilidade e de respeito aos direitos humanos sobre a preponderante evolução econômica predadora.

\section{REFERÊNCIAS}

ANAYA, S. James. Los pueblos indígenas em el derecho internacional. Tradução de Luis Rodrigues-Piñero Royo; Pablo Gutierrez Veja; Bartolomé Clavero. New York, USA: Ed.Trota, 2004. 
ANTUNES, Paulo de Bessa. Direito Ambiental. 14 Ed. São Paulo: Atlas, 2012.

ARTINGAS, Priscila Santos. A Democracia participativa na Gestão do Ambiente Urbano. In: AMBIENTAL ENFOQUES VARIADOS. Org. Bruno Campos da Silva. Lemos Cruz Livraria e Editora, 2004.

BRASIL, Eloi Cesar Danieli; SOBRINHO, Liton Lanes Pilau. Meio ambiente e consumo tratamento jurídico no Brasil. In: RELAÇÕES DE CONSUMO: Meio Ambiente. Org. Agostinho Oli Kopper Pereira, Luiz Fernando Del Rio Horn. Caxias do Sul, RS. Educs, 2009.

BRASIL. Constituição (1988). Constituição da República Federativa do Brasil. Brasília, DF: Senado Federal: Centro Gráfico, 1988.

FRANÇOSI, Ronaldo José. Transferência compulsória de indígenas e a dignidade da pessoa humana. Insular, 2015.

GRIJALVA, Agustín. El Estado plurinacional e intercultural en la Constitución ecuatoriana de 2008. In: Pueblos Indígenas constituciones y reformas políticas en América Latina. 1 ed. Lima: Raquel Z. Yrigoren Fajardo Editora, 2010.

MARTÍNEZ DALMAU, Rúben; VICIANO PASTOR, Roberto. O processo constituinte venezuelano no marco do novo constitucionalismo latino-americano. In: WOLKMER, Antônio Carlos; MELO, Milena Petters. Constitucionalismo latino-americano: tendências contemporâneas. Curitiba: Juruá, 2013.

MACHADO, Paulo Afonso Leme. Direito Ambiental Brasileiro. 17 Ed. Malheiros Editores Ltda. 2009.

RECH, Adir Ubaldo. A sociedade de consumo e o desenvolvimento sustentável. In: RELAÇÕES DE CONSUMO: Meio Ambiente. Org. Agostinho Oli Kopper Pereira, Luiz Fernando Del Rio Horn. Caxias do Sul, RS: Educs, 2009.

SILVA, Orlando Sampaio. Os Povos Indígenas e o Estado Brasileiro: Sociedades indígenas e o direito: uma questão de direitos humanos. Org. Silvio Coelho dos Santos. Florianópolis, UFSC, 1985.

SIRVINSKAS, Luís Paulo. Manual de Direito Ambiental. Editora Saraiva, 2009.

\section{FONTES ELETRÔNICAS}

BORGES, Gustavo Silveira; CARVALHO, Marina Moura Lisboa Carneiro de Farias. O Novo Constitucionalismo latino-americano e as inovações sobre os Direitos da Natureza na Constituição Equatoriana. In: Revista da Faculdade de Direito da UFG, v.43, 2019. Disponível em: <https://www.revistas.ufg.br/revfd/article/view/48710.> Acesso em: 19 nov. 2019.

COMISSÃO ECONÔMICA PARA A AMÉRICA LATINA E CARIBE (CEPAL). Os Povos Indígenas na América Latina. Avanços na última década e desafios pendentes para a 
garantia de seus direitos. Síntese. Santigo/Chile, 2015. Disponível em: <https://repositorio.cepal.org/.> Acesso em: 18 nov. 2019.

. (CEPAL/ONU). Los pueblos indígenas en América Latina. Avances en el último decenio y retos pendientes para la garantía de sus derechos. Síntesis. Chile: Imprensa Oficial, 2015. Disponível em http://www.cepal.org/es/publicaciones. Acesso em: 19 de nov. 2019.

COMISSÃO NACIONAL DE DIREITOS HUMANOS (CNDH). Megaproyectos y derechos humanos de los pueblos indígenas. Disponível em:

http://www.cndh.org.mx/sites/all/doc/cartillas/2015-2016/02-DH-Pueblos-indigenas.pdf. Acesso em: 16 nov. 2019.

Organização das Nações Unidas (ONU). Relatório da $1^{\text {a }}$ Conferência Mundial sobre os Povos Indígenas. Nova Iorque, 2014. Disponível em: https://nacoesunidas.org. Acesso em: 19 de novembro 2019.

MALISKA, Marcos Augusto. MOREIRA, Parcelli Dionizio. O Caso Vilcabamba e EI Buen Vivir na Constituição do Equador de 2008: pluralismo jurídico e um novo paradigma ecocêntrico. 2017 Disponível em:

<file:///C:/Users/Usuario/Desktop/Nova\%20pasta\%20(2)/2177-7055-seq-77-149.pdf.>

Acesso em: 03 de dez. 2019.

ORGANIZAÇÃO INTERNACIONAL DO TRABALHO (OIT). Convenio 169. Disponível em: <http://www.ilo.org/indigenous/Conventions/no169/.> Acesso em: 18 nov. 2019.

ORGANIZAÇÃO DAS NAÇÕES UNIDAS - ONU. 5 coisas que você precisa saber sobre a Conferência da ONU sobre o Clima. 2019. Disponível em: <https://nacoesunidas.org/5coisas-que-voce-precisa-saber-sobre-a-conferencia-da-onu-sobre-o-clima/.> Acesso em: 08 dez. 2019.

SAMPAIO, RÔMULO. Direito ambiental. FGV DIREITO RIO. 2015. Disponível em: <https://direitorio.fgv.br/sites/direitorio.fgv.br/files/u100/direito_ambiental_2015-2.pdf.> Acesso em: 03 dez. 2019. 